\title{
Changing associations between partnership history and risk of accidents, violence and suicides
}

\section{Silventoinen, Karri}

2013-03

Silventoinen , K, Moustgaard , H , Peltonen , R \& Martikainen , P 2013 , ' Changing associations between partnership history and risk of accidents, violence and suicides ' ,

Journal of Epidemiology \& Community Health , vol. 67 , no. 3 , pp. 265-270 . https://doi.org/10.1136/jech-2012-2013

http://hdl.handle.net/10138/234030

https://doi.org/10.1136/jech-2012-201311

acceptedVersion

Downloaded from Helda, University of Helsinki institutional repository.

This is an electronic reprint of the original article.

This reprint may differ from the original in pagination and typographic detail.

Please cite the original version. 
Changing associations between partnership history and risk of accidents, violence and suicides

\author{
Karri Silventoinen, ${ }^{1} \mathrm{PhD}$ \\ Heta Moustgaard, ${ }^{1}$ MSocSci \\ Riina Peltonen, ${ }^{1}$ BSocSci \\ Pekka Martikainen, ${ }^{1} \mathrm{PhD}$, professor
}

${ }^{1}$ Population Research Unit, Department of Social Research, University of Helsinki, Finland

Word count: 250 (abstract) $+3110($ text $)$

Key words: partnership history; marital status; accidents; violence; suicide

Contact address:

Karri Silventoinen, $\mathrm{PhD}$

Population Research Unit

Department of Social Research

P.O. Box 18

00014 University of Helsinki

Finland

Phone: 358-9-19127572

Fax: 358-9-19127570

E-mail: karri.silventoinen@helsinki.fi 


\begin{abstract}
Background: Lower mortality has been systematically found in married when compared to non-married, especially in men, but little is known about marital status differences in mortality from external causes. Further the role of cohabitation and partnership history in the formation of these differences and how they have been changed over time are poorly understood.
\end{abstract}

Methods: The incidence of fatal and non-fatal cases of accidents, violence and suicides by partnership history was analyzed during 1991-1997 and 2001-2007 in a representative sample of the Finnish population aged 26-59. Hazard ratios (HR) were calculated using Cox proportional hazards models.

Results: Incidence rates in accidents, violence and suicides were generally lower in men and women living with a partner than those living alone. Current cohabitation and previous divorce increased the risk of all of these outcomes when compared to married without previous divorce. Higher incidence rates were found in men who had divorced three years ago or earlier when compared to those who had divorced later. Generally these differences were larger in fatal than in non-fatal cases and significantly larger in men. There was little change in these differences between 1991-1997 and 2001-2007. These differences were partly explained by socio-economic factors, but remained statistically significant also after these adjustments.

Conclusions: Not only currently living without a partner but also cohabitation and previous divorce increased the risk of accidents, violence and suicides. This indicates that also other 
mechanisms than immediate support from a partner are important in the formation of marital status differences in mortality. 


\section{What is already known on this subject?}

Non-married persons have higher mortality than married and the highest mortality is in divorced men.

\section{What this study adds?}

Not only living without a partner but also cohabiting and previous divorce history are associated with higher incidence of accidents, violence and suicides in men and women when compared to married without previous divorce. In addition to immediate support from a partner also other factors, such as selection mechanisms, may underlie marital status differences in mortality. 


\section{INTRODUCTION}

Lower mortality in married persons when compared to never-married and especially divorced has been persistently shown in previous studies $(1,2)$, and during the last two decades the association between marital status and mortality has become even stronger $(3,4)$. This trend toward widening mortality differences between marital status groups is somewhat surprising since at the same time divorce rates have increased in all western countries and both divorce and being non-married have become socially more acceptable (5). An issue that has received only little attention so far is, however, marital status differences in external causes even though injuries and suicides are the leading causes of death in young adults in many industrialized countries (6). Mortality from accidents and violence is also much higher in males than in females, and thus it can partly explain high mortality in non-married men leading to larger mortality differences according to marital status in males than in females (7).

The most widely studied external cause of death according to marital status is suicide, and previous studies have consistently shown that suicide mortality is lower in married than in non-married men and women (8). A comparative study of marital status differences in suicides in eight European countries also found that suicide rates were not only lower but also socio-economic differences were narrower in married than in the non-married group suggesting buffering effect of marriage against the negative effects of low social position (9). Previous Finnish studies have found that the risk difference between married and non-married persons was even higher in deaths from external causes than in total mortality (3) and 
somewhat higher risk has also been found for cohabiting when compared to married Finns in both young (10) and middle-aged adults (11).

A limitation in these previous studies is that they have analyzed only current partnership status. Further there are no studies analyzing whether the increased risk related to cohabitation has changed in time when it has become increasingly common in most western countries (12). Also in previous studies no distinction has been made between accidents and being a victim of violence even when these two forms of death may be differently associated with marital status. Furthermore, only a partial understanding of the phenomena under scrutiny can be achieved by studying mortality only and thus excluding non-fatal cases. For example when suicides are generally more common in males, suicide attempts are more common in females (8). We therefore analyzed partnership history differences in the incidence of both fatal and non-fatal injuries, differentiating between injuries due to accidents, violence and suicides and assessing how these associations have changed from 1991-1997 to 2001-2007 using Finnish population registers.

\section{DATA AND METHODS}

\section{Participants and follow-up}

The study cohort was formed by linkage between registers covering the whole Finnish population using unique personal identification numbers assigned to every Finnish resident. The data include a representative $11 \%$ sample of the whole Finnish population during 19872007 with an $80 \%$ over-sample of the population that died during this period. From these data two analytical sub-sets with similar structure were created. At baseline years 1990 and 2000, 
information on current partnership status, history of divorce, and current socioeconomic position was extracted from the registers of the Statistics Finland. The analyses were restricted to those older than 25 years and younger than 60 years of age at baseline. There were two 7-year follow-up periods of 1991-1997 and 2001-2007.

Information on non-fatal incidence of accidents and violence during the follow-ups was based on the hospital discharge register by the National Institute of Health and Welfare of Finland, and information on fatal injuries on the mortality register held by the Statistics Finland. International Classification of Diseases (ICD) revisions of 9 and 10 were used. We included those cases with injury as a diagnosis (ICD9: 800-995; ICD10: S00-T79, T90-T98) and further categorized the non-fatal and fatal outcomes according to the classification of external causes into accidents (ICD9: E800-E859, E880-E929; ICD10: V00-X59), intentional selfharm (ICD9: E950-E959; ICD10: X60-X84, Y87.0) and interpersonal violence (ICD9: E960-E969; ICD10: X85-X99, Y87.1, Y00-Y09). Because of the universal health care system in Finland, the hospital discharge register covers the whole Finnish population and includes virtually all non-fatal cases needing hospital level care. According to the Finnish law, also the mortality register covers the whole Finnish population. Altogether we had 407,814 participants (42\% women) in 1990 and 317,929 participants (47\% women) in 2000. Among these participants, there were 14551 deaths from accidents, 844 from violence and 7654 from suicides for the period of 1991-1997 whereas the numbers of deaths for the period of 2001-2007 were 16230,617 and 5974, respectively. The numbers of non-fatal cases were 93973,2574 , and 4442 for the period of 1991-1997 and 76144,1762 and 3046 for the period of 2001-2007, respectively.

\section{Measurement of covariates}


Partnership status was classified as married, cohabiting, divorced, never-married and widow(er). However we excluded all widow(er)s from the analyses because this group was small (1.6\% in 1990 and $1.3 \%$ in 2000) and was heavily concentrated in the oldest age groups. Those currently divorced were classified to those whose divorce had happened less than three years ago and those who had divorced three years ago or earlier. Information on marriage and divorce was based on the population register and information on cohabitation on linkage between the population and household registers; two non-married persons living together were defined as cohabiting if they were of different sex, not siblings and their age difference was less than 16 years.

The models were adjusted for having any children under 18-years of age living in the household as a binary variable, education (basic education only, secondary education, lower tertiary education, upper tertiary education and $\mathrm{PhD}$ education), economic activity (employed, unemployed, student, pensioner and other), social class (upper non-manual, lower non-manual with independent work or subordinates, lower non-manual with routine work, specialized manual, non-specialized manual, farmer, entrepreneur, no previous occupation), and household taxable income per consumption unit. Incomes were derived from the Tax Administration database including all annual taxable incomes and social benefits. Consumption units were calculated using the modified OECD equivalence scale (first adult contribute 1.0, subsequent persons 13 -years of age or older contribute 0.5 and children less than 13 years contribute 0.3 ). Income per consumption unit was used as a continuous variable and all other socioeconomic covariates as categorical variables in the statistical models.

\section{Statistical methods}


We calculated hazard ratios (HR) with $95 \%$ confidence intervals (CI) for partnership history status separately for non-fatal and fatal outcomes of accidents, violence and suicides first adjusted only for age at baseline and then adjusted for all socioeconomic covariates. Cox proportional hazards models were used. Age was adjusted using it as a stratum variable classified into 5-year intervals and also including it as a continuous variable into the models. Those migrated or died from other causes during the follow-up were treated as cencored cases. Further we tested interaction effects of partnership history with gender and study period. The over sample of deaths was taken into account when calculating the proportions or participants in partnership history categories, incidence rates and HRs by using sample weights which denote the inverse of the probability that the observation is included because of the sampling design. All analyses were conducted using the Stata statistical software, version 10.1 for Windows.

\section{RESULTS}

Table 1 presents the distribution of participants and age adjusted incidence rates per 100000 person years for accidents, violence and suicides by partnership history status. The proportion of married men and women had decreased from the year 1990 to 2000 and at the same time cohabiting and being never-married had become more common. Also divorces had become more prevalent which is reflected as a higher proportion of both divorced men and women as well as those currently married but who had experienced at least one divorce. Generally the incidence rates of all outcomes were much higher for males than for females. The exception was attempted suicide where incidence rates were at the same level in males and females in spite of the much higher suicide mortality rate in males. Clear difference in the incidence 
rates were found between partnership history categories with the lowest incidence rates in married men and women who had not divorced before. The highest incidence rates were generally found in divorced men.

Table 2 presents HRs for fatal and non-fatal accidents, violence and suicides by partnership history in men. For all of these outcomes, the incident rates were lowest in married without previous divorce used as the reference category $(\mathrm{HR}=1.00)$. Systematically those currently living with a partner (married or cohabiting) had lower incidence rates than those living without a partner (divorced and never-married). The largest differences between the partnership history categories were seen in violence whereas the risk differences in accidents and suicides were lower and roughly at the same level. However the general pattern of partnership history categories was very similar for all of these outcomes: the risk was somewhat increased in cohabiting men, higher in unmarried men and for most outcomes highest in divorced. Previous divorce increased the risk for accidents, violence and suicides in men currently married or cohabiting. In divorced men the risk was higher in those whose divorce had happened three years ago or earlier when compared to men who had experienced the divorce later; this was especially the case for violence where very high risk among men divorced three years ago or earlier was found. Similar results were found when treating partnership status and divorce history as separate variables (Appendix table 1). Adjusting the results for socio-economic factors attenuated the differences between partnership history categories but they still remained: the decrease in HRs varied from less than $10 \%$ to more than $60 \%$ and for most categories of partnership history varied between $30 \%$ and $40 \%$. No systematic differences between the two time periods were found in the effect of partnership history, and the interaction terms between partnership history status and study period were not statistically significant $(\mathrm{p}=0.13-0.84)$. Fatal and non-fatal cases showed generally similar 
pattern of the partnership history differences, but the risk estimates were generally lower for non-fatal than for fatal cases.

Table 3 presents the results for corresponding analyses in women. Similarly to men, the HRs were somewhat higher for violence than for accidents and suicides, but the general pattern of differences between the partnership history categories was similar for all of these outcomes. Correspondingly to men, the lowest risk was found in married women who had not divorced previously whereas the risk of cohabiting women was somewhat higher. Such as in men, both in married and cohabiting groups a previous divorce increased the risk of accidents, violence and suicides also in women. Somewhat higher risk was also found for divorced and nevermarried women, but contrast to men these risk estimates were generally at the same level than in married and cohabiting women experienced a previous divorce or even lower. In contrast to men, the risk of violence was higher in women divorced less than three years ago than in those who had divorced earlier. This difference become even more visible in the analyses treating partnership status and divorce history as separate variables (Appendix table 2). The partnership history differences were significantly smaller in women than in men for both periods and for all outcomes ( $\mathrm{p}=0.001-0.03$ ) except for suicides in the period 1991-1997 and suicides and attempted suicides in the period 2001-2007 ( $\mathrm{p}=0.15-0.24)$. Adjusting the results for socio-economic covariates attenuated the differences between the marital history categories also in women, but the general pattern remained also after these adjustments. The decrease in the HRs was, however, less than found in men and was generally less than $40 \%$. The interaction effect between partnership history status and study period was statistically significant for accidents ( $\mathrm{p}=0.02$ for fatal and 0.04 for non fatal cases) but no systematic pattern was seen; for the other outcomes the interaction effects were statistically nonsignificant $(\mathrm{p}=0.05-0.97)$. 


\section{DISCUSSION}

We found that the differences in the incidence of accidents, violence and suicides between the partnership history categories were roughly similar than found in previous studies for total mortality $(1,2)$. The married had the lowest incidence and the highest incidence rates were found in never-married and especially divorced men and women. Furthermore in accordance with previous studies, we found that these differences were larger in men than in women and especially high risks for all of these outcomes were found in divorced men (7). It is noteworthy that the differences between the partnership history categories were largest in deaths due to interpersonal violence. A previous Finnish study based on the national police register found that from 1960 to 2000 both the offenders and victims of homicides were mainly from the lowest social stratum of the Finnish society (13). Thus marginalization indicated by low social position and not living with a partner seems to be an important risk factor for interpersonal violence in Finland.

Marital status differences in mortality have been explained both by selection of those with higher risk factor profile to the unmarried groups and protective effects of being married, and both of these hypotheses have received some empirical support. It is well known that low education and poor socioeconomic position decrease the likelihood of getting married in men (14) and increase the risk of divorce in both men and women (15). There is also evidence that psychiatric disorders (16) and low psychological well-being in young age (17) decrease the likelihood of getting married in men and women. On the other hand, being married has been found to decrease alcohol consumption (18) and divorce can also increase psychological stress (19). Heavy alcohol consumption strongly increases risk of accidents (20), violence 
(21) and suicides (22). Further, being married can increase economic security (23). In our study adjusting for socio-economic factors diminished the relative risks of accidents, violence and suicides between the partnership history categories from $10 \%$ to nearly $60 \%$; socioeconomic factors explained systematically larger proportion of these differences in men than in women and this was especially the case in divorced and never-married categories. This indicates that the socio-economic structure of the partnership history categories is different, which contributes to the found mortality differences by marital status. Not only current partnership status but also the history of divorce was associated with increased risk of accidents, violence and suicides. This may indicate the role of selection but also the effect of long term psychological stress related to living without a spouse.

We found that in both males and females, cohabitation was associated with higher risk of accidents, violence and suicides when compared to the married such as reported previously for suicides and deaths from all accidents (11). These results are in accordance with previous studies which have found higher prevalence of mental health problems (24) and heavy alcohol use in cohabiting compared to married couples (25). These differences can be both because of different protective effect of marriage and cohabitation or selection of persons to these categories according to risk factor profile. We found some evidence for the latter explanation since a considerable part of the differences between married and cohabited was explained by the socio-economic covariates, but also after these adjustments the differences were found. Interestingly we found that the higher risks related to cohabitation when compared to married had not systematically changed from 1991-1997 to 2001-2007 even when at the same time cohabitation had increased from about $10 \%$ to $15 \%$. These results suggest that there are persistent differences in the risk factor profile between married and cohabiting couples not related to socio-economic factors 
Difference in total mortality between married and unmarried groups has been found to become wider from 1990 to 2000 across Europe (4), and a previous Finnish study found a similar trend in deaths from external causes from 1976-80 to 1996-2000 (3). In the light of these findings, it is interesting that we did not find systematic changes in the partnership history patterning of violence, accidents and suicides from 1991-1997 to 2001-2007. This can be because the trend leading toward widening mortality differences would have leveled off in our latter follow-up period extending to 2000s, but our results may also offer another explanation. During the period of widening marital status differences in mortality, cohabitation has become more common in all Western countries (12). Since the relative risk of external causes of death is increased in cohabiting men and women, it is possible that marriage has become increasingly selected group according to low risk factor profile.

We found that the differences between partnership history categories were larger in fatal than in non-fatal cases of accidents and violence. This indicates that partnership history is associated not only with the prevalence but also with the seriousness of accidents and violence. Correspondingly a Finnish study based both on the national police register and survey data found that socioeconomic differences were widest when studying victimization in the most violent crimes (26). Interestingly, however, in suicides this association was somewhat different and when cohabiting men showed a higher rate of attempted suicide when compared to married men, this difference was much weaker in suicide mortality. This may be because men living in an intimate relationship may receive emergency medical care more quickly after a suicide attempt. However, similar difference was not found in women. 
Our data have strengths but also limitations. Our main strengths are that we have large and register based data with follow-up covering the whole Finnish population and thus not prone to self-selection, misreporting and loss to follow-up. We also had information on cohabitation and history of divorce and further information not only on mortality but also on non-fatal cases. A limitation of our study is that because we had to rely only on register based data, we did not have information on health behavioral and other risk factors. Further studies using questionnaire based information are needed to elucidate which factors explain these associations. Because we had information only on hospitalizations but not actual events, we used Cox model also for non-fatal cases and thus selected only the first hospitalization. It is well possible that those persons in high risk of, for example, accident have also higher risk for further accidents. However this has no effect on relative risks between the marital history categories.

In conclusion not only current partnership status but also the history of divorce is associated with the risk for accidents, violence and suicides. This suggests that not only current support received when living in an intimate relationship but also other mechanisms, such as selection to different partnership categories, are important in the formation of marital status differences in mortality.

\section{ACKNOWLEDGEMENTS}

This work was supported by the Academy of Finland.

\section{Licence for Publication}


The Corresponding Author has the right to grant on behalf of all authors and does grant on behalf of all authors, an exclusive licence (or non exclusive for government employees) on a worldwide basis to the BMJ Publishing Group Ltd and its Licensees to permit this article (if accepted) to be published in JECH editions and any other BMJPGL products to exploit all subsidiary rights, as set out in our licence (http://group.bmj.com/products/journals/ instructions-for-authors/licence-forms/).

\section{Competing Interest}

None declared.

\section{Funding Statement}

This work was supported by the Academy of Finland grant numbers 1255388 and 1250569 .

\section{Contributorship Statement}

KS and PM created the study design. KS conducted the analyses and wrote the paper. RP was in charge of data management and helped to write the data description. HM helped in statistical analyses. All authors have contributed to interpretation the results and critically revising the manuscript. 


\section{REFERENCES}

(1) $\mathrm{Hu}$ YR, Goldman N. Mortality differentials by marital status: an international comparison. Demography 1990;27:233-250.

(2) Rendall MS, Weden MM, Favreault MM, et al. The protective effect of marriage for survival: a review and update. Demography 2011;48:481-506.

(3) Martikainen P, Martelin T, Nihtilä E, et al. Differences in mortality by marital status in Finland from 1976 to 2000: analyses of changes in marital-status distributions, sociodemographic and household composition, and cause of death. Pop Stud 2005;59:99-115.

(4) Murphy M, Grundy E, Kalogirou S. The increase in marital status differences in mortality up to the oldest age in seven European countries, 1990-99. Pop Stud 2007;61:287-298.

(5) Lyngstad TH, Jalovaara M. A review of the antecedents of union dissolution. Dem Res 2010;23:257-292.

(6) Blum RW, Nelson-Mmari K. The health of young people in a global context. J Adolesc Health 2004;35:402-418.

(7) Staehelin K, Schindler C, Spoerri A, et al. Marital status, living arrangement and mortality: does the association vary by gender? J Epidemiol Community Health 2011.

(8) Cantor CH. Suicides in the Western World. In: Hawton K, van Heeringen K, editors. Suicide and Attempted Suicide Chichester: Wiley; 2000. p. 9-28.

(9) Lorant V, Kunst AE, Huisman M, et al. A European comparative study of marital status and socio-economic inequalities in suicide. Soc Sci Med 2005;60:2431-2441.

(10) Remes HM, Martikainen P. Living arrangements and external causes of deaths in early adulthood. Adol Health 2012;50:164-171.

(11) Koskinen S, Joutsenniemi K, Martelin T, et al. Mortality differences according to living arrangements. Int J Epidemiol 2007;36:1255-1264.

(12) Kiernan K. The rise of cohabitation and childbearing outside marriage in Western Europe. Int J Law Policy Family 2001;15:1-21.

(13) Kivivuori J, Lehti M. The social composition of homicide in Finland, 1960-2000. Acta Sociol 2006;49:67-82.

(14) Koskinen S, Martelin T. Why are socioeconomic mortality differences smaller among women than among men? Soc Sci Med 1994;38:1385-1396.

(15) Jalovaara M. Socio-economic status and divorce in first marriages in Finland 1991-93. Pop Stud 2001;55:119-133. 
(16) Lund R, Holstein BE, Osler M. Marital history from age 15 to 40 years and subsequent 10-year mortality: a longitudinal study of Danish males born in 1953. Int J Epidemiol 2004;33:389-397.

(17) Mastekaasa A. Marriage and psychological well-being: some evidence on selection into marriage. J Marriage Family 1992;54:901-911.

(18) Power C, Rodgers B, Hope S. Heavy alcohol consumption and marital status: disentangling the relationship in a national study of young adults. Addiction 1999;94:14771487.

(19) Hemström Ö. Is marriage dissolution linked to differences in mortality risks for men men and women? J Marriage Family 1996;58:366-378.

(20) Skog OJ. Alcohol consumption and mortality rates from traffic accidents, accidental falls, and other accidents in 14 European countries. Addiction 2001;96:S49-S58.

(21) Borges G, Cherpitel CJ, Orozco R, et al. Acute alcohol use and the risk of non-fatal injury in sixteen countries. Addiction 2006;101:993-1002.

(22) Murphy GE. Psychiatric aspects of suicidal behavior: substance abuse. In: Hawton K, van Heeringen K, editors. Suicide and Attempted Suicide Chichester: Wiley; 2000. p. 135146.

(23) Hahn BA. marital status and women's health: the effect of economic marital acquisition. J Marriage Family 1993;55:495-504.

(24) De Klyen M, Brooks-Gunn J, McLanahan S, et al. The mental health of married, cohabiting, and non-coresident parents with infants. Am J Public Health 2006;96:1836-1841.

(25) Joutsenniemi K, Martelin T, Kestilä L, et al. Living arrangements, heavy drinking and alcohol dependence. Alcohol Alcohol 2007;42:480-491.

(26) Aaltonen ME, Kivivuori J, Martikainen P, et al. Socioeconomic differences in violent victimization: exploring the impact of data source and the inclusivity of the violence concept. Eur J Crimino 2012;in print. 
Table 1. Distribution of study participants and age-adjusted incidence rates of accidents, violence and suicides per 100000 person years by partnership history. ${ }^{1}$

$\begin{array}{lccc}\text { Participants } & \text { Accidents } & \text { Violence } & \text { Suicides } \\ \% & \text { fatal cases non-fatal cases } & \text { fatal cases non-fatal cases } & \text { fatal cases non-fatal cases }\end{array}$

Men 1991-1997

Married (no divorce) $\quad 60.8$

Married (previously divorced) $\quad 2.5$

Cohabiting (no divorce) $\quad 8.1$

Cohabiting (previously divorced) 3.2

Divorced less than 3 years ago $\quad 2.0$

Divorced 3 years ago or earlier $\quad 4.0$

Never-married $\quad 19.4$

Total 100

Men 2001-2007

Married (no divorce) $\quad 50.3$

Married (previously divorced) $\quad 4.2$

Cohabiting (no divorce) $\quad 11.6$

Cohabiting (previously divorced) 4.0

Divorced less than 3 years ago $\quad 2.0$

Divorced 3 years ago or earlier $\quad 6.1$

Never-married

21.8

Total

$\begin{array}{ll}43.9 & 734.8 \\ 86.0 & 972.3 \\ 98.8 & 842.4 \\ 116.9 & 1166.6 \\ 178.7 & 1202.7 \\ 277.8 & 1501.0 \\ 180.9 & 1033.2 \\ 84.4 & 850.2\end{array}$

$\begin{array}{ll}2.4 & 12.6 \\ 6.7 & 48.1 \\ 6.8 & 46.5 \\ 9.2 & 78.8 \\ 15.6 & 49.8 \\ 38.7 & 85.8 \\ 14.6 & 15.8 \\ 6.5 & 51.1\end{array}$

$39.1 \quad 31.9$

$82.2 \quad 112.4$

$60.2 \quad 71.7$

$81.8 \quad 107.7$

$142.2 \quad 145.7$

$155.9 \quad 233.7$

$101.7 \quad 82.6$

$60.3 \quad 57.2$

$\begin{array}{llllll}39.6 & 1049.7 & 1.3 & 23.1 & 25.4 & 32.4 \\ 80.5 & 1316.8 & 4.2 & 85.7 & 61.8 & 97.4 \\ 67.0 & 1206.5 & 4.8 & 54.5 & 33.6 & 46.5 \\ 80.2 & 1372.3 & 7.8 & 121.5 & 47.3 & 51.1 \\ 157.9 & 1789.7 & 10.4 & 165.2 & 77.7 & 130.6 \\ 251.6 & 1841.7 & 15.5 & 232.7 & 98.5 & 276.5 \\ 161.9 & 1425.5 & 10.3 & 99.4 & 71.7 & 87.2 \\ 85.1 & 1229.3 & 5.0 & 61.5 & 41.8 & 60.0\end{array}$


Women 1991-1997

Married (no divorce)

65.9

Married (previously divorced)

Cohabiting (no divorce)

Cohabiting (previously divorced)

Divorced less than 3 years ago

Divorced 3 years ago or earlier $\quad 5.9$

Never-married

Total

13.0

100

Women 2001-2007

Married (no divorce)

Married (previously divorced)

Cohabiting (no divorce)

Cohabiting (previously divorced) 4.2

Divorced less than 3 years ago

Divorced 3 years ago or earlier

Never-married

Total

$\begin{array}{ll}12.8 & 423.9 \\ 31.5 & 587.7 \\ 29.2 & 609.2 \\ 49.6 & 706.5 \\ 36.3 & 696.5 \\ 43.0 & 621.7 \\ 27.1 & 549.2 \\ 19.3 & 481.2\end{array}$

12.8

28.5

27.4

38.2

27.8

45.9

36.4

21.8
1.5

4.9

2.9

8.5

10.0

4.8

2.4

2.5

\begin{abstract}
1.0
\end{abstract}
2.9

3.4

4.5

2.0

4.1

1.5

1.6
12.6

48.1

46.5

78.8

49.8

85.8

15.8

21.9

8.1

36.5

15.7

49.7

45.6

45.4

24.3

18.1
$10.2 \quad 40.3$

$31.3 \quad 138.4$

$13.9 \quad 62.3$

$25.6 \quad 112.2$

$32.3 \quad 124.1$

$38.9 \quad 135.4$

$32.3 \quad 77.4$

$16.6 \quad 57.1$

$8.1 \quad 34.8$

$24.6 \quad 132.7$

$12.6 \quad 55.5$

$20.2 \quad 112.2$

$25.8 \quad 118.7$

$29.3 \quad 150.2$

$22.8 \quad 74.4$

$13.9 \quad 62.7$

${ }^{1}$ The total number of individuals and events are not displayed but are available only in the Method section because of over sample of deaths. This over sample is taken into account when calculating the proportions and incidence rates. 
Table 2. Hazard ratios (HR) with $95 \%$ confidence intervals (CI) of accidents, violence and suicides for partnership history by case fatality in men. ${ }^{1}$

Fatal cases

Years 1991-1997

Married (no divorce)

Married (previously divorced)

Cohabiting (no divorce)

Cohabiting (previously divorced)

Divorced less than 3 years ago

Divorced 3 years ago or earlier

Never-married

\section{Years 2001-2007}

Married (no divorce)

Married (previous divorce)

Cohabiting (no divorce)

Cohabiting (previous divorce)

Divorced less than 3 years ago

Divorced 3 years ago or earlier

Never-married

Cohort*partnership history
Accidents

$\begin{array}{ll}\text { Model } 1 & \text { Model } 2 \\ \text { HR 95\% CI } & \text { HR 95\% CI }\end{array}$

Violence

$\begin{array}{ll}\text { Model 1 } & \text { Model } 2 \\ \text { HR 95\% CI } & \text { HR 95\% CI }\end{array}$

1.00

$\begin{array}{llll}3.51 & 1.96-6.27 & 2.70 & 1.46-4.97\end{array}$

$\begin{array}{lllll}2.77 & 1.82-4.23 & 1.60 & 1.02-2.53\end{array}$

$\begin{array}{llll}4.01 & 2.45-6.58 & 2.40 & 1.42-4.04\end{array}$

$\begin{array}{llll}7.08 & 4.40-11.40 & 3.67 & 2.12-6.36\end{array}$

$\begin{array}{llll}14.51 & 10.69-19.71 & 5.42 & 3.71-7.93\end{array}$

$\begin{array}{llll}6.23 & 4.74-8.18 & 2.57 & 1.86-3.54\end{array}$
Suicides

$\begin{array}{ll}\text { Model 1 } & \text { Model 2 } \\ \text { HR 95\% CI } & \text { HR 95\% CI }\end{array}$

$\begin{array}{llll}1.00 & & 1.00 & \\ 2.00 & 1.67-2.39 & 1.87 & 1.56-2.24 \\ 1.29 & 1.12-1.47 & 0.99 & 0.86-1.15 \\ 2.01 & 1.72-2.36 & 1.62 & 1.38-1.91 \\ 3.46 & 2.95-4.05 & 2.81 & 2.38-3.33 \\ 3.59 & 3.19-4.04 & 2.48 & 2.17-2.82 \\ 2.57 & 2.38-2.78 & 1.71 & 1.56-1.87\end{array}$

$1.00 \quad 1.00$

$\begin{array}{llll}1.90 & 1.58-2.28 & 1.74 & 1.45-2.10\end{array}$

$\begin{array}{llll}1.19 & 1.02-1.39 & 0.93 & 0.79-1.09\end{array}$

$\begin{array}{llll}1.85 & 1.53-2.22 & 1.50 & 1.24-1.81\end{array}$

$\begin{array}{llll}3.10 & 2.53-3.80 & 2.42 & 1.95-3.00\end{array}$

$\begin{array}{llll}3.46 & 3.05-3.92 & 2.20 & 1.91-2.53\end{array}$

$\begin{array}{llll}2.87 & 2.61-3.16 & 1.70 & 1.52-1.90\end{array}$ $\mathrm{p}=0.13$ 
Non-fatal cases

Years 1991-1997

Married (no divorce)

$\begin{array}{lll}1.00 & 1.00 & 1.00\end{array}$

$1.00 \quad 1.00$

Married (previous divorce)

$1.32 \quad 1.16-1.49 \quad 1.26 \quad 1.11-1.43$

$2.94 \quad 1.82-4.74 \quad 2.35 \quad 1.45-3.81$

1.00

1.00

Cohabiting (no divorce)

$\begin{array}{llll}1.17 & 1.07-1.27 & 1.02 & 0.94-1.12\end{array}$

$2.96 \quad 2.16-4.06$

$1.73 \quad 1.24-2.42$

$\begin{array}{llll}3.83 & 2.71-5.41 & 3.37 & 2.39-4.76\end{array}$

Cohabiting (previous divorce)

$\begin{array}{llll}1.48 & 1.33-1.65 & 1.32 & 1.18-1.47\end{array}$

$\begin{array}{llll}3.52 & 2.38-5.20 & 2.07 & 1.38-3.09\end{array}$

$\begin{array}{llll}5.56 & 3.71-8.32 & 3.29 & 2.13-5.08\end{array}$

$\begin{array}{llll}11.919 .24-15.35 & 4.81 & 3.56-6.50\end{array}$

Divorced 3 years ago or earlier

$\begin{array}{llll}1.66 & 1.46-1.88 & 1.48 & 1.30-1.69\end{array}$

$2.03 \quad 1.88-2.19 \quad 1.61 \quad 1.48-1.75$

$\begin{array}{llll}1.38 & 1.30-1.45 & 1.11 & 1.05-1.18\end{array}$

$4.49 \quad 3.58-5.62 \quad 2.11 \quad 1.65-2.71$

$2.06 \quad 1.58-2.68 \quad 1.44 \quad 1.09-1.90$

$3.23 \quad 2.35-4.46 \quad 2.29 \quad 1.64-3.20$

$\begin{array}{llll}4.16 & 3.02-5.72 & 3.07 & 2.17-4.34\end{array}$

$\begin{array}{llll}5.06 & 3.91-6.56 & 2.52 & 1.87-3.39\end{array}$

Never-married

$\begin{array}{llll}1.00 & & 1.00 & \\ 1.17 & 1.07-1.29 & 1.15 & 1.05-1.27 \\ 1.17 & 1.10-1.25 & 1.06 & 1.00-1.14 \\ 1.33 & 1.22-1.45 & 1.23 & 1.12-1.34 \\ 1.70 & 1.52-1.90 & 1.54 & 1.37-1.73 \\ 1.92 & 1.80-2.04 & 1.60 & 1.50-1.72 \\ 1.34 & 1.27-1.40 & 1.08 & 1.03-1.14 \\ \mathrm{p}=0.51 & & \end{array}$

$\begin{array}{llll}1.00 & & 1.00 & \\ 4.33 & 2.91-6.44 & 3.18 & 2.09-4.85 \\ 2.43 & 1.76-3.35 & 1.78 & 1.28-2.48 \\ 3.94 & 2.61-5.94 & 2.79 & 1.84-4.24 \\ 7.56 & 5.07-11.29 & 4.62 & 2.96-7.19 \\ 10.688 .12-14.05 & 4.70 & 3.45-6.39 \\ 4.57 & 3.56-5.86 & 2.32 & 1.77-3.03 \\ p=0.28 & & \end{array}$

$\begin{array}{llll}1.00 & & 1.00 & \\ 3.47 & 2.48-4.87 & 2.95 & 2.09-4.17 \\ 1.51 & 1.13-2.02 & 1.09 & 0.81-1.47 \\ 2.01 & 1.35-2.98 & 1.49 & 0.99-2.22 \\ 3.62 & 2.39-5.48 & 2.02 & 1.28-3.20 \\ 4.96 & 3.80-6.48 & 2.37 & 1.77-3.18 \\ 2.67 & 2.16-3.30 & 1.22 & 0.97-1.54 \\ \mathrm{p}=0.31 & & & \end{array}$

Model 1: Adjusted for age

Model 2: Adjusted for age, having children, incomes per consumption unit, education, economic activity and socio-economic status

${ }^{1}$ The over sample of deaths is taken into account in the Cox proportional hazards models. 
Table 3. Hazard ratios (HR) with $95 \%$ confidence intervals (CI) of accidents, violence and suicides for partnership history by case fatality in women. ${ }^{1}$

\begin{tabular}{|c|c|c|c|}
\hline \multicolumn{4}{|c|}{ Accidents } \\
\hline \multicolumn{2}{|c|}{ Model 1} & \multicolumn{2}{|c|}{ Model 2} \\
\hline HR & $95 \%$ CI & HR & $95 \% \mathrm{CI}$ \\
\hline 1.00 & & 1.00 & \\
\hline 2.52 & $1.94-3.29$ & 2.03 & $1.55-2.67$ \\
\hline 1.90 & $1.47-2.47$ & 1.36 & $1.04-1.77$ \\
\hline 3.82 & $3.09-4.70$ & 2.75 & $2.21-3.42$ \\
\hline 2.69 & $2.00-3.61$ & 2.37 & $1.74-3.23$ \\
\hline 2.99 & $2.52-3.55$ & 2.50 & $2.07-3.02$ \\
\hline $\begin{array}{l}2.17 \\
p<0.0\end{array}$ & $\begin{array}{l}1.85-2.56 \\
01\end{array}$ & 1.42 & $1.18-1.71$ \\
\hline
\end{tabular}

$\begin{array}{llll}1.00 & & 1.00 & \\ 2.18 & 1.74-2.73 & 1.79 & 1.43-2.26 \\ 1.88 & 1.52-2.33 & 1.49 & 1.20-1.85 \\ 3.13 & 2.56-3.81 & 2.39 & 1.96-2.93 \\ 2.04 & 1.47-2.85 & 1.66 & 1.16-2.36 \\ 3.18 & 2.74-3.70 & 2.47 & 2.11-2.89 \\ 2.86 & 2.46-3.31 & 1.86 & 1.57-2.19 \\ \mathrm{p}<0.001 & & \\ \mathrm{p}=0.02 & & & \end{array}$

Violence

Model $1 \quad$ Model 2

HR $95 \%$ CI HR $95 \%$ CI

Fatal cases

Years 1991-1997

Married (no divorce)

Married (previous divorce)

Cohabiting (no divorce)

Cohabiting (previous divorce)

Divorced less than 3 years ago

Divorced 3 years ago or earlier

Never-married

Gender*partnership history

Years 2001-2007

Married (no divorce)

Married (previous divorce)

Cohabiting (no divorce)

Cohabiting (previous divorce)

Divorced less than 3 years ago

Divorced 3 years ago earlier

Never-married

Gender*partnership history

Cohort*partnership history $\mathrm{p}=0.02$
Suicides

$\begin{array}{ll}\text { Model 1 } & \text { Model } 2 \\ \text { HR 95\% CI } & \text { HR 95\% CI }\end{array}$

$\begin{array}{llll}1.00 & & 1.00 & \\ 2.50 & 1.85-3.38 & 2.17 & 1.61-2.94 \\ 1.60 & 1.23-2.09 & 1.17 & 0.88-1.55 \\ 2.57 & 1.95-3.39 & 1.94 & 1.47-2.57 \\ 3.37 & 2.52-4.50 & 2.97 & 2.20-4.01 \\ 3.25 & 2.67-3.96 & 2.78 & 2.26-3.43 \\ 3.19 & 2.73-3.72 & 2.18 & 1.83-2.59 \\ \mathrm{p}=0.24 & & & \end{array}$

$1.00 \quad 1.00$

$\begin{array}{llll}2.73 & 2.10-3.57 & 2.27 & 1.73-2.99\end{array}$

$\begin{array}{llll}1.38 & 1.06-1.81 & 1.09 & 0.82-1.43\end{array}$

$2.40 \quad 1.81-3.19 \quad 1.95 \quad 1.46-2.60$

$\begin{array}{lllll}3.03 & 2.16-4.26 & 2.47 & 1.73-3.53\end{array}$

$\begin{array}{llll}3.53 & 2.91-4.28 & 2.68 & 2.20-3.28\end{array}$

$\begin{array}{lllll}2.83 & 2.36-3.39 & 1.70 & 1.38-2.08\end{array}$

$\mathrm{p}=0.16$

$\mathrm{p}=0.97$ 
Non-fatal cases

Years 1991-1997

Married (no divorce)

$\begin{array}{llll}1.00 & & 1.00 & \\ 1.27 & 1.08-1.50 & 1.21 & 1.02-1.42 \\ 1.31 & 1.16-1.49 & 1.21 & 1.06-1.38 \\ 1.71 & 1.49-1.95 & 1.55 & 1.36-1.78 \\ 1.68 & 1.42-1.98 & 1.55 & 1.31-1.84 \\ 1.41 & 1.27-1.56 & 1.29 & 1.15-1.44 \\ 1.33 & 1.22-1.45 & 1.16 & 1.05-1.28 \\ \mathrm{p}<0.0001 & & \end{array}$

$\begin{array}{lllllllll}1.00 & & 1.00 & & 1.00 & & 1.00 & \\ 3.24 & 1.79-5.86 & 2.53 & 1.38-4.64 & 3.01 & 2.15-4.21 & 2.47 & 1.75-3.48 \\ 2.93 & 1.87-4.57 & 2.23 & 1.39-3.58 & 1.13 & 0.80-1.58 & 0.84 & 0.59-1.19 \\ 6.65 & 4.40-10.05 & 4.23 & 2.71-6.59 & 2.81 & 2.02-3.89 & 2.01 & 1.42-2.84 \\ 4.23 & 2.37-7.54 & 4.21 & 2.31-7.69 & 3.28 & 2.30-4.69 & 2.85 & 1.96-4.16 \\ 4.82 & 3.17-7.32 & 4.47 & 2.83-7.06 & 3.18 & 2.44-4.14 & 2.54 & 1.91-3.38 \\ 1.39 & 0.88-2.19 & 1.18 & 0.71-1.97 & 1.90 & 1.51-2.40 & 1.27 & 0.97-1.67 \\ \mathrm{p}<0.0001 & & & \mathrm{p}=0.03 & & & \end{array}$

Years 2001-2007

Married (no divorce)

$\begin{array}{llll}1.00 & & 1.00 & \\ 1.51 & 1.35-1.68 & 1.43 & 1.28-1.60 \\ 1.09 & 0.98-1.20 & 1.03 & 0.93-1.13 \\ 1.59 & 1.43-1.77 & 1.49 & 1.34-1.67 \\ 1.46 & 1.25-1.70 & 1.39 & 1.18-1.63 \\ 1.65 & 1.53-1.78 & 1.52 & 1.40-1.64 \\ 1.35 & 1.26-1.46 & 1.17 & 1.07-1.27 \\ \mathrm{p}<0.0001 & & \\ \mathrm{p}=0.04 & \end{array}$

$\begin{array}{llll}1.00 & & 1.00 & \\ 4.77 & 2.64-8.63 & 3.47 & 1.92-6.29 \\ 1.77 & 1.01-3.12 & 1.47 & 0.83-2.60 \\ 6.99 & 4.17-11.71 & 4.64 & 2.75-7.82 \\ 5.23 & 2.64-10.35 & 4.07 & 2.02-8.21 \\ 5.16 & 3.16-8.42 & 3.04 & 1.80-5.12 \\ 3.01 & 1.93-4.70 & 2.06 & 1.24-3.40 \\ p=0.01 & & & \\ p=0.05 & & & \end{array}$

$1.00 \quad 1.00$

$\begin{array}{llll}3.80 & 2.81-5.13 & 3.03 & 2.25-4.09\end{array}$

$\begin{array}{lllll}1.35 & 0.99-1.84 & 1.04 & 0.77-1.42\end{array}$

$\begin{array}{llll}3.30 & 2.40-4.55 & 2.43 & 1.77-3.35\end{array}$

$\begin{array}{llll}3.56 & 2.42-5.24 & 3.11 & 2.10-4.59\end{array}$

$\begin{array}{llll}4.62 & 3.65-5.84 & 3.39 & 2.67-4.31\end{array}$

$\begin{array}{llll}2.27 & 1.80-2.86 & 1.47 & 1.14-1.90\end{array}$ $\mathrm{p}=0.15$

$\mathrm{p}=0.58$

Model 1: Adjusted for age

Model 2: Adjusted for age, having children, incomes per consumption unit, education, economic activity and socio-economic status

${ }^{1}$ The over sample of deaths is taken into account in the Cox proportional hazards models. 